\title{
Delayed Eruption of Permanent Teeth in an Adolescent With Down's Syndrome: A Case Report
}

\author{
Yuanyuan Wanga, Yuming Zhao ${ }^{\mathrm{a}}$, Lihong Ge $\mathrm{Ge}^{\mathrm{a}, \mathrm{b}}$
}

\begin{abstract}
A case of a 15-year-old Chinese girl with Down's syndrome is presented in this report. Besides the common clinical manifestations for persons with Down's syndrome, the girl has a rare oral anomaly, which is the delayed eruption of all the permanent teeth with primary dentition retained.
\end{abstract}

Keywords: Down's syndrome; Delayed eruption; Permanent teeth

\section{Introduction}

Down's syndrome is also known as trisomy 21 , trisomy $\mathrm{G}$, and mongolism. It is an autosomal disorder with an incidence of $1 / 700$, caused by an extra chromosome 21 . The first description of a child who presumably had Down's syndrome was provided by Esquirol in 1838 .

Delayed eruption in Down's children could influence both primary and permanent teeth. For deciduous dentition, tooth eruption is delayed in timing and sequence, like the primary dentition, first eruption in permanent dentition is delayed. Six years old molars and mandibular incisors may not erupt until the age of 8 - 9 years [1]. The chronologic sequence of eruption in Down's syndrome is not much different from the general population. The least affected teeth are upper and lower first molars and central and lateral incisors. Asymmetries between sides of the jaw mainly affect the canines and asymmetry seems to be less frequent between 7 and 9 years of age and more frequent between 10 and 14 years of age. Despite this, children with Down's syndrome maintain a certain similarity in sequence and symmetry compared with normal children.

\footnotetext{
Manuscript accepted for publication April 29, 2015

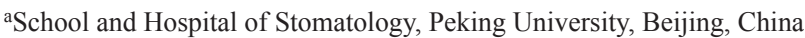
${ }^{\mathrm{b} C}$ Corresponding Author: Lihong Ge, Department of Pediatric Dentistry, Peking University School and Hospital of Stomatology, \#22 Zhongguancun Nandajie, Haidian District, Beijing 100081, China. Email: gelh0919@126.com
}

doi: http://dx.doi.org/10.14740/jmc2166w

\section{Case Report}

In July 2012, a 15-year-old Chinese girl with Down's syndrome with no shedding of the deciduous teeth and delayed eruption of her permanent teeth was brought by her parents to the Department of Pediatric Dentistry, Peking University School and Hospital of Stomatology. The patient presented with moderate mental retardation; she had a history of delayed speech and developmental milestones.

On general examination, she looked short and small stature. Hands, feet, and digits were broad and shortened. Her weight was $45 \mathrm{~kg}$ and height was $130 \mathrm{~cm}$. The skin of the facial area appeared dry. Extraoral examination revealed a round cherubic face, a broad forehead, microcephaly, slanting eyes, flat nasal bridge, flattening of the occiput, and a broad and short neck. The medicine and family history were unremarkable.

The clinical intraoral examination revealed an open mouth, macroglossia and a protruding tongue, a primary dentition with some tooth decays (tooth primary maxillary central incisors, primary maxillary left second molar, primary mandibular left first molar, primary mandibular right first and second molar) and a gingival fistula (primary maxillary left first molar) in the upper left posterior area (Fig. 1a). No permanent tooth was found. Her oral hygiene was poor. The maxillary arch was narrow and the mandible arch was broad. The palatal vault was narrow and short. Radiographic examination revealed the permanent teeth were impacted, the upper incisors were dilacerated and both sides of the second upper premolars were missing (Fig. 1b). The patient was cooperative for dental treatment, and primary incisors were extracted and the permanent incisors were exposed under local anesthesia at different times. After 2 years the permanent incisors erupted (Fig. 2).

\section{Discussion}

In Down's syndrome, eruption of the deciduous and permanent teeth is delayed as compared with general population. The causes of delayed eruption in Down's children are unknown, due to lack of information on the factors intervening in the process of normal eruption. Nevertheless, the delayed eruption in Down's children seems to be dependent on the trisomic state. Bone resorption occurs during eruption in normal children; this process may be depressed in Down's children [2]. 
a
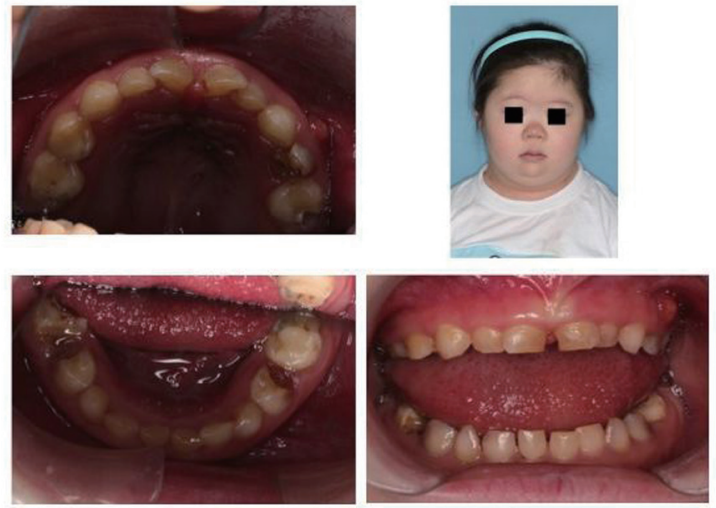

b

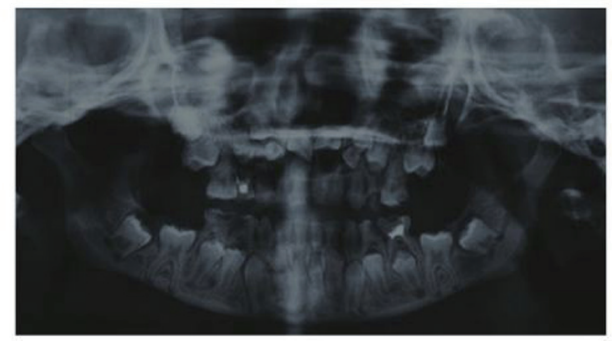

Figure 1. Intraoral view and the facial appearance of the patient at the initial visit demonstrating short neck, short nose and anterior open bite, also the oral status showing an primary dentition with teeth decays and a gingival fistula (a). Panoramic radiograph of the patient at age of 15 years (at initial visit) (b).

There is suggestive evidence that the rate of eruption is influenced by the vascularity of the periradicular connective tissue [2]. The poor peripheral circulation in Down's syndrome could be a factor leading to delayed eruption. The delay may be a part of the delay in growth and development that characterizes this syndrome; the growth of both the maxilla and mandible is retarded. Some have correlated the low weight at birth with the delayed dental eruption $[3,4]$.

In this case, we reported a rare condition with none eruption of the permanent tooth even until 15 years old which is far beyond the range of the eruption time of the Down's children, and it indicated that delayed tooth eruption is one of the dental characteristics of the Down's children, which could influence both the deciduous and the permanent dentition. The eruption time would vary to a large-scale regional.

This report is important for our pediatric dentistry; though a
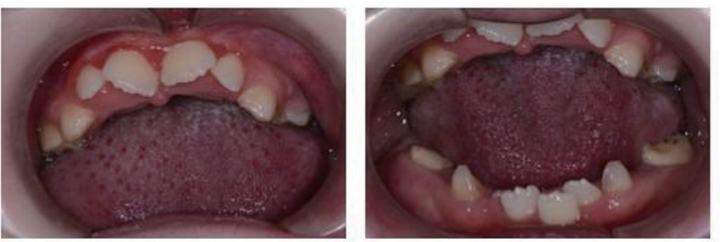

b

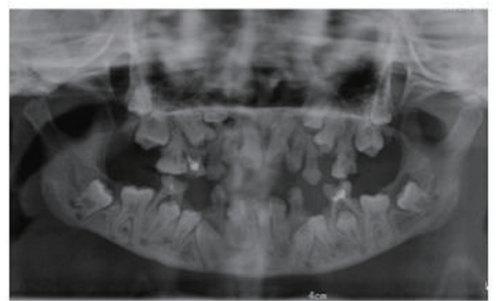

Figure 2. Intraoral view of the patient after 2 years follow-up demonstrating the permanent incisors erupted after extracting the primary incisors and exposing the permanent incisors (a). Panoramic radiograph of the patient at age of 17 years (at 2 years follow-up) (b).

tooth eruption was significantly delayed and root development was completed in Down's children, after primary tooth extraction, the impacted permanent tooth has the probability of spontaneous eruption; it suggested routine dental consultation (3 - 6 months) is calling for the Down's children for oral condition evaluation. Especially for evaluating the dentition replacement, early meddle with the teeth eruption would be beneficial for the Down's children.

\section{References}

1. Jara L, Ondarza A, Blanco R, Valenzuela C. The sequence of eruption of the permanent dentition in a Chilean sample with Down's syndrome. Arch Oral Biol. 1993;38(1):8589.

2. Roche AF, Barkla DH. The development of the dentition in mongols. Austr. dent. J. 1967;12:12-16.

3. Delgado H, Habicht JP, Yarbrough C, Lechtig A, Martorell R, Malina RM, Klein RE. Nutritional status and the timing of deciduous tooth eruption. Am J Clin Nutr. 1975;28(3):216-224.

4. Trupkin DP. Eruption patterns of the first primary tooth in infants who were underweight at birth. ASDC J Dent Child. 1974;41(4):279-282. 